CLINICAL STUDY

\title{
GH deficiency with central precocious puberty: a new rare disorder associated with a developmental defect of the hypothalamic-pituitary area
}

Asmahane Ladjouze, Sylvie Soskin ${ }^{1}$, Catherine Garel $^{2}$, Marc Jullien $^{3}$, Catherine Naud-Saudreau ${ }^{4}$, Graziella Pinto ${ }^{5}$, Paul Czernichow and Juliane Léger

Pediatric Endocrinology Department, Reference Center for Rare Endocrine Growth Diseases, Assistance Publique-Hôpitaux de Paris, Robert Debré Hospital, Paris VII University, Paris, France, ${ }^{1}$ Pediatrics Department of Hautepierre Hospital, Strasbourg, France, ${ }^{2}$ Radiology Department, Robert Debré Hospital Paris, Paris, France, ${ }^{3}$ Pediatrics Department of Troyes Hospital, Troyes, France, ${ }^{4}$ Pediatrics Department of Lorient Hospital, Lorient, France and ${ }^{5}$ Pediatric Endocrinology Department, Necker Enfants Malades Hospital, Paris, France

(Correspondence should be addressed to J Léger; Email: juliane.leger@rdb.aphp.fr)

\begin{abstract}
Context: GH deficiency (GHD) associated with central precocious puberty (CPP) has been widely reported in cases of arachnoid cyst, septo-optic dysplasia, brain tumors, or after cerebral radiation therapy. However, idiopathic GHD associated with CPP has been reported in only one isolated case. Objective: To evaluate the occurrence and clinical features of the association of nonacquired GHD and CPP.

Design and setting: This was a retrospective multicenter study.

Patients and methods: The study population was identified through a French nationwide multicenter network (about 3000 patients). We reviewed the medical records of all subjects diagnosed with nonacquired GHD and CPP, with or without developmental abnormalities of the hypothalamic-pituitary axis on cerebral magnetic resonance imaging (MRI), and without any known associated anomaly. Results: We identified four patients with either isolated GHD $(n=1)$ or multiple anterior pituitary hormone deficiencies $(n=3)$. Clinical signs of CPP occurred at $6.4 \pm 2.3$ years in boys and $7.5 \pm 0.5$ years in girls, and GnRH analog therapy was started at $4.2 \pm 1.6$ years after the initiation of recombinant human GH treatment. Cerebral MRI demonstrated ectopic neurohypophysis associated with anterior pituitary hypoplasia in three out of the four patients. The morphology and position of the anterior pituitary and neurohypophysis were normal in one patient who displayed a persistence of the craniopharyngeal canal.

Conclusions: CPP is very rare in patients with nonacquired GHD and is mostly associated with developmental defects in the hypothalamic-pituitary area. Whether molecular mechanisms governing development and activation of the hypothalamic-pituitary axis share dependent factors remains to be explored.
\end{abstract}

European Journal of Endocrinology 156 463-469

\section{Introduction}

The association of idiopathic growth hormone deficiency (GHD) and central precocious puberty (CPP) has been exceptionally reported in only one isolated case (1). However, GHD has been reported to be associated with CPP in cases of arachnoid cyst (2-5), septo-optic dysplasia (6-10), brain tumors in the pituitary region, or after cerebral radiation therapy, particularly if administered as prophylaxis against acute lymphoblastic leukemia (11-13). This association has also been reported in very rare cases after a head injury $(7,13)$. This endocrine association represents a further risk of short stature. It is known to involve the hypothalamus area, but its physiopathology remains unclear. Improving the phenotypic characterization of such patients might shed light in the future on the mechanisms that underlie these intriguing endocrine manifestations. This retrospective study was designed to investigate the occurrence and the clinical features of this unusual rare association of nonacquired GHD and CPP, without any known associated anomaly, i.e. arachnoid cyst or septo-optic dysplasia.

\section{Patients and methods}

\section{Patients}

A recent national survey indicated that, in France, $\approx 4130$ patients (age $<20$ years and male ratio $=1.6$ ) were treated with recombinant human $\mathrm{GH}(\mathrm{hGH})$ for GHD, in the year 2000. Among them, $\approx 702$ patients 
(17\%) demonstrated acquired GHD and 3428 patients demonstrated nonacquired GHD, giving an incidence of 1 out of 4134 for nonacquired GHD patients (14). Pediatricians were involved in the follow-up of most of them (14). The study population was identified through a French nationwide multicenter network by means of a questionnaire sent to all the pediatric endocrinologists $(n=96)$. Eighty-five percent of them responded. They were responsible for about 3000 patients with nonacquired GHD. We reviewed the medical records of all subjects diagnosed with nonacquired GHD and CPP, with or without developmental abnormalities of the hypothalamic-pituitary axis on cerebral magnetic resonance imaging (MRI), and without any known associated anomaly, i.e. arachnoid cyst or septo-optic dysplasia. Four patients with this combination of endocrine disorders were identified.

\section{Methods}

GHD was diagnosed on the basis of a GH peak below $20 \mathrm{mIU} / \mathrm{l}$ in two different pharmacological tests. GH secretion was stimulated with arginine insulin $(n=1)$, ornithine $(n=4)$, glucagon betaxolol $(n=1)$, glucagon $(n=1)$, and/or L-dopamine (L-dopa; $n=1)$. All other anterior pituitary functions were evaluated in all patients at diagnosis and this evaluation was repeated during the follow-up if deemed necessary based on clinical examination, serum-free thyroxine (T4), and morning cortisol concentrations. Thyrotropin deficiency was defined as a plasma-free $\mathrm{T} 4$ concentration lower than $10 \mathrm{pmol} / \mathrm{l}$, and/or abnormal stimulation after thyrotropin-releasing hormone (TRH) administration (the normal values for thyrotropin (TSH) were $0.5-6,14$, and $<8 \mathrm{mIU} / \mathrm{l}$ for the basal, peak, and T120 mn levels respectively). Adrenocorticotropin (ACTH) deficiency was defined as a plasma cortisol level lower than $165 \mathrm{nmol} / \mathrm{l}$ in basal conditions and lower than $415 \mathrm{nmol} / \mathrm{l}$ during insulin-induced hypoglycemia. If morning cortisol concentration exceeded $275 \mathrm{nmol} / \mathrm{l}$, corticotropin reserves were not systematically evaluated. Since patients were prepubertal at the time of GHD diagnosis, gonadotropin status was not evaluated at that time.

Precocious puberty (PP) has been defined as the onset of clinical signs of puberty before the age of 9 years in boys (testicular enlargement) and before 8 years in girls (breast development). The hypothalamic-pituitarygonad axis was assessed by measuring gonadotropin responses in the gonadotropin-releasing hormone $(\mathrm{GnRH})$ stimulation test $\left(100 \mathrm{ug} / \mathrm{m}^{2}\right.$ intravenous administration; central PP diagnosed if luteinizing hormone peak $>5 \mathrm{IU} / \mathrm{l}$ ) and plasma concentrations of testosterone in boys and estradiol in girls. Girls also underwent pelvic ultrasound scans.

Height, growth velocity, weight, and body mass index (BMI; weight $(\mathrm{kg}) /$ height $\left.(\mathrm{m})^{2}\right)$ were expressed as the SDS for sex and chronological age $(15,16)$. Pubertal development was assessed as described by Tanner (17). Bone age was determined by the Greulich and the Pyle method (18). Target height was calculated from midparental height (19).

Cerebral MRI was carried out at GHD diagnosis. A second MRI evaluation was carried out at the time of PP diagnosis. All MRI scans were reviewed by the same investigator (CG) blind to endocrinological data. Sagittal and coronal $3 \mathrm{~mm}$ slices of the pituitary area were obtained using a gradient-echo T1-weighted sequence and axial slices of the brain using a T2-weighted sequence. Gadolinium was injected and the pituitary stalk was recorded as present or absent before and after gadolinium administration. The height of the anterior pituitary was measured on a sagittal T1-weighted image and was judged to be either normal or hypoplasic according to normative data in children (20). The anterior pituitary was considered to be hypoplasic if its height was $<-2$ s.D. for age (20). The precise location of the posterior pituitary hypersignal was established by MRI. We also checked for other associated brain abnormalities on MRI.

Adverse perinatal events, such as breech presentation, cesarean section, forceps delivery, or neonatal distress (low Apgar score or neonatal resuscitation) were recorded. Birth weight and length were expressed as SDS for gestational age and sex. Children were described as small for gestational age (SGA) if they had a birth weight and/or birth length below -2 SDS (21). We also checked for associated congenital malformations and/or other acquired diseases and abnormal development.

Informed consent for evaluation and treatment was obtained from the children's parents and patients.

Results are expressed as the mean \pm s.D.

\section{Results \\ Clinical characteristics at diagnosis of GHD and CPP}

In all patients ( $n=4,2$ males, 2 females; all Caucasian subjects), GHD was first diagnosed. Patient characteristics at that time are shown in Table 1. GHD was suspected early in life and was diagnosed at a mean age of $2.1 \pm 1.4$ years (from 0.8 to 3.5 years), because of a height deficit $(n=2)$, decrease in height velocity $(n=1)$, or hypoglycemia $(n=1)$. None of the boys had micropenis or cryptorchidism. None of the patients presented adverse perinatal events or neonatal distress and one patient was born SGA. Patients had either isolated GHD $(n=1)$ or multiple anterior pituitary hormone deficiencies $(n=3)$ with thyrotropin deficiency in all. ACTH deficiency was diagnosed 2 years after GHD in one patient. Serum prolactin levels were either normal $(n=3)$ or low $(n=1)$. hGH was given at a dose of $0.037 \pm 0.01 \mathrm{mg} / \mathrm{kg}$ per day, inducing catch-up growth in all cases (growth velocity of $+3.9 \pm 1.9$ SDS in the first year of treatment). Additional replacement therapy with 
Table 1 Clinical characteristics of the patients at growth hormone deficiency (GHD) diagnosis.

\begin{tabular}{|c|c|c|c|c|}
\hline Patient & 1 & 2 & 3 & 4 \\
\hline Sex & M & M & $\mathrm{F}$ & $\mathrm{F}$ \\
\hline Gestational age (weeks of amenorrhea) & 41 & 40 & 40 & 41 \\
\hline Birth weight (SDS) & -0.17 & +0.22 & +0.04 & +1.84 \\
\hline Birth length (SDS) & -2.0 & -0.8 & - & +0.5 \\
\hline Target height (SDS) & -0.1 & +1.4 & -1.3 & -0.6 \\
\hline Chronological age (years) & 1 & 3.5 & 3 & 0.75 \\
\hline Bone age (years) & - & 1 & 3 & 0 \\
\hline Height (SDS) & -3.9 & -1.3 & -0.5 & -2.4 \\
\hline Growth velocity (SDS) & -2.1 & -1.4 & -0.5 & -1.3 \\
\hline BMI (SDS) & +0.9 & -1 & -1.9 & +2.4 \\
\hline Clinical signs of GHD & Short stature & Decrease in growth velocity & Hypoglycemia & Short stature \\
\hline GH 1 st test $(\mathrm{mlU} / \mathrm{l})$ & $1^{\mathrm{O}}$ & $11^{\mathrm{gb}}$ & $10^{\circ}$ & $2^{\mathrm{g}}$ \\
\hline $\mathrm{GH}$ 2nd test (mIU/l) & $0.8^{\mathrm{ai}}$ & $13^{\circ}$ & $4.4^{\mathrm{Id}}$ & $2^{\circ}$ \\
\hline TSH base/peak/T120 under TRH (mIU/l) & 0.01 & 3 & $5 / 27 / 23$ & $2 / 13 / 5$ \\
\hline T4 I (pmol/l) & 8.9 & 9.7 & 8.5 & 17.3 \\
\hline PRL base/peak/T120 (ng/ml) & 0.9 & $13 / 22 / 13$ & 12 & $8 / 26 / 8$ \\
\hline Cortisol $8 \mathrm{~h} /$ in hypoglycemia $(\mathrm{nmol} / \mathrm{l})$ & $320 / 604$ & 350 & $127^{\star}$ & 276 \\
\hline Pituitary deficiency & $\mathrm{GH}+\mathrm{TSH}$ & $\mathrm{GH}+\mathrm{TSH}$ & $\mathrm{GH}+\mathrm{TSH}+\mathrm{ACTH}^{*}$ & $\mathrm{GH}$ \\
\hline
\end{tabular}

${ }^{\circ}$, Ornithine; ${ }^{9}$, Glucagon; ${ }^{\text {b }}$, Glucagon Bxolol; ${ }^{\text {ai }}$, Arginine insulin; ${ }^{\text {ld }}$, L-Dopa pharmacological tests. Abnormal values are indicated in bold type. *Diagnosed 2 years after GHD diagnosis.

L-thyroxine and hydrocortisone was given when TSH and ACTH deficiencies were diagnosed.

Clinical signs of PP occurred at a mean age of $6.4 \pm$ 2.3 years in boys and $7.5 \pm 0.5$ years in girls (Table 2 ). GnRH tests were performed at the age of $7.0 \pm 3.1$ years for boys and $8.4 \pm 0.2$ years for girls, demonstrating CPP. GnRH therapy was started at that time $4.2 \pm 1.6$ years after the initiation of hGH treatment.

\section{Cerebral MRI findings}

Ectopic neurohypophysis was found in three out of the four patients. In one patient (patient 1), the morphology and position of the anterior pituitary and neurohypophysis were normal, but a congenital midline abnormality was detected, with persistence of the craniopharyngeal canal (Fig. $1 \mathrm{a}$ and b). The ectopic neurohypophysis (Fig. 1c and d) was located at the median eminence with no visibility of the pituitary stalk $(n=2)$ or in the proximal portion of the pituitary stalk with a visible pituitary stalk $(n=1)$. In all cases, ectopic neurohypophysis was associated with anterior pituitary hypoplasia. The results of the second MRI were similar to those for the first, but pituitary height decreased between the two MRI in one patient (Table 3).

Table 2 Clinical characteristics of the patients at central precocious puberty (CPP) diagnosis.

\begin{tabular}{|c|c|c|c|c|}
\hline Patient & 1 & 2 & 3 & 4 \\
\hline Age at first pubertal signs (years) & 4.7 & 8 & 7.9 & 7 \\
\hline Age at evaluation (years) & 4.8 & 9.2 & 8.2 & 8.5 \\
\hline Tanner score & 2.0 & 2.0 & 2.0 & 2.0 \\
\hline Pubertal signs & $\mathrm{P} 1 \mathrm{~T} 35 \times 20$ & $\mathrm{P} 1 \mathrm{~T} 35 \times 20$ & $\mathrm{P} 1 \mathrm{~B} 2$ & P1B2 \\
\hline Bone age - chronological age (years) & 0.3 & -1.0 & +2.3 & +1.5 \\
\hline Growth velocity (SDS) & +2.3 & +6.3 & +0.5 & +1.8 \\
\hline Height (SDS) & -0.2 & +2.3 & +1.3 & +1.8 \\
\hline Height gain since start of hGH treatment (SDS) & +3.7 & +3.6 & +1.8 & +4.2 \\
\hline BMI (SDS) & +0.8 & +0.9 & -0.4 & +1.7 \\
\hline Change in BMI since GHD diagnosis (SDS) & -0.1 & +1.9 & +1.5 & -0.7 \\
\hline \multicolumn{5}{|l|}{ LHRH test } \\
\hline FSH base/peak (IU/l) & $1.9 / 8$ & $3.1 / 5.9$ & $3.6 / 10.4$ & $6 / 9.5$ \\
\hline LH base/peak (IU/I) & $0.4 / 13.6$ & $0.7 / 7.4$ & $0.5 / 7.2$ & $0.8 / 9$ \\
\hline Testosterone & 3.9 & 0.5 & & \\
\hline Estradiol & & & 24 & $<3$ \\
\hline DHEAS (ng/ml) & $<60$ & 140 & $<60$ & - \\
\hline \multicolumn{5}{|l|}{ Uterine height (mm) } \\
\hline Ultrasonography & & & 44 & 35 \\
\hline Time between the beginning of $\mathrm{hGH}$ treatment and CPP diagnosis & 3.5 & 2.6 & 4.9 & 5.9 \\
\hline
\end{tabular}

Abnormal values are indicated in bold type. 

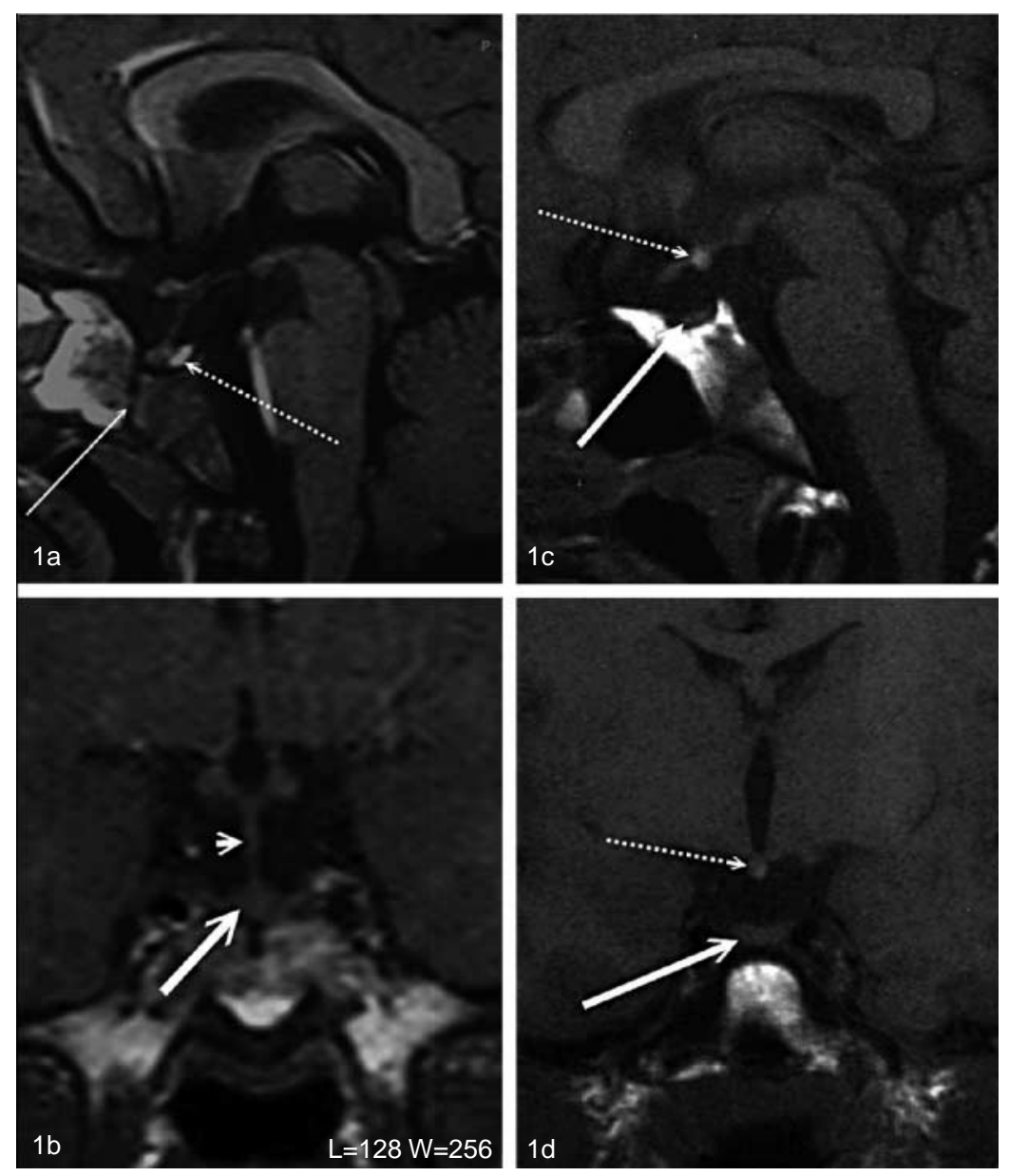

Figure 1 Magnetic resonance imaging focused on the hypothalamic-pituitary axis. T1-

weighted slices without gadolinium injection in patient 1 (1a, 1b) and patient $3(1 \mathrm{c}, 1 \mathrm{~d})$.

1a: Midline sagittal slice: the pituitary gland is normal in appearance (dotted arrow; the hyperintense signal of the posterior pituitary is in the normal location). Note the persistence of the craniopharyngeal canal (arrow). 1b: Coronal slice: normal morphology of the anterior pituitary (thick arrow) and the pituitary stalk

(arrowhead) is seen. 1c and 1d: Midline sagittal and coronal slices: hypoplastic anterior pituitary (thick arrow) with no visible pituitary stalk. The ectopic pituitary hyperintense signal is at the median eminence (dotted arrow).

\section{Evolution}

Mean age at last evaluation was $12.9 \pm 4.1$ years (between 7.3 and 16.8 years). GnRH analog therapy had been stopped in three patients (patients 2, 3 and 4), after $3.4 \pm 0.7$ years of treatment, but is ongoing in the fourth patient (patient 1, Table 4). Puberty was completed in two patients (patients 2 and 3). One of them (patient 3) has been treated with progestative drugs for irregular menstrual cycles.

Treatment with hGH is continuing in two patients (patients 1 and 4) and was stopped in the other two patients (patients 2 and 3) at a mean age of $14.2 \pm 0.5$ years.

One patient was overweight and presented hyperphagia and hypersomnia (patient 1), and two patients have presented an increase in BMI of +1.8 SDS and + 3 SDS since the diagnosis of GHD (patients 2 and 3 respectively). Patient 4 was overweight at the time of GHD diagnosis, but BMI has since been normalized through dietary restrictions. Three patients presented slight $(n=2$, patients 1 and 3$)$ or severe $(n=1$, patient 2) psychomotor retardation. One patient has been on anticonvulsive treatment for 10 years (patient 3). No familial history of hypothalamic-pituitary dysfunction has been reported.

\section{Discussion}

We report here the first detailed phenotypic characterization of a series of four patients with both nonacquired GHD and GnRH-dependent sexual precocity, and without any known associated anomaly, i.e. arachnoid cyst or septo-optic dysplasia. One patient with multiple anterior pituitary hormone deficiencies presented no anatomical abnormalities of the pituitary gland. Cerebral MRI showed a minor midline cranial structure defect-persistence of the craniopharyngeal canal, which has been shown to be a congenital developmental abnormality possibly associated with nonacquired GHD $(22,23)$. In the other patients, this combination of endocrine disorders was associated with ectopic neurohypophysis and anterior pituitary hypoplasia. As previously shown in patients with GHD and ectopic neurohypophysis (24), patients with an ectopic neurohypophysis located at the median eminence and no visible pituitary stalk presented a more severe form of 
Table 3 Magnetic resonance imaging (MRI) characteristics of the hypothalamic-pituitary area.

\begin{tabular}{|c|c|c|c|c|}
\hline Patient & 1 & 2 & 3 & 4 \\
\hline Age (years) MRI 1 & 1.0 & 3.8 & 4.0 & 1.0 \\
\hline Age (years) MRI 2 & 4.8 & 9.3 & 8.7 & 9.5 \\
\hline \multicolumn{5}{|l|}{ Pituitary gland height } \\
\hline MRI 1 (mm) & $4 \mathrm{~mm}$ & $2.5 \mathrm{~mm}$ & $2.8 \mathrm{~mm}$ & Not visible \\
\hline MRI 2 (mm) & $4 \mathrm{~mm}$ & $3 \mathrm{~mm}$ & $1.5 \mathrm{~mm}$ & $2 \mathrm{~mm}$ \\
\hline \multicolumn{5}{|l|}{ Pituitary gland } \\
\hline MRI 1 & Normal & Hypoplasic & Hypoplasic & Hypoplasic \\
\hline MRI 2 & Normal & Hypoplasic & Hypoplasic & Hypoplasic \\
\hline \multicolumn{5}{|l|}{ Pituitary stalk } \\
\hline MRI 1 & Present & Not viewed & Not viewed & Present \\
\hline MRI 2 & Present & Not viewed & Not viewed & Present \\
\hline \multicolumn{5}{|l|}{ Neurohypophysis } \\
\hline MRI 1 & In place & Not viewed & $\begin{array}{c}\text { Ectopic } \\
\text { (median eminence) }\end{array}$ & Not viewed \\
\hline MRI 2 & In place & $\begin{array}{c}\text { Ectopic } \\
\text { (median eminence) }\end{array}$ & $\begin{array}{c}\text { Ectopic } \\
\text { (median eminence) }\end{array}$ & $\begin{array}{l}\text { Ectopic (proximal portion } \\
\text { of the pituitary stalk) }\end{array}$ \\
\hline Other findings & $\begin{array}{l}\text { Persistence of the } \\
\text { craniopharyngeal canal }\end{array}$ & None & None & None \\
\hline
\end{tabular}

the disease, with multiple anterior hormone deficiencies (TSH and ACTH deficiencies), whereas visibility of the pituitary stalk and an ectopic neurohypophysis located at some point along the stalk was associated with isolated GHD.

Except in patients with brain tumors and after cerebral irradiation (11-13), the association of a pituitary deficiency and CPP is extremely rare.

In France, $16(0.5 \%)$ out of the 3165 patients with GHD who started hGH treatment before 1990, have been identified with this combination, whatever the etiology, idiopathic, organic, or radiation induced (25). Moreover, among the 42206 patients from 47 countries who entered in the KIGS database (August 2002), 249 (0.6\%) subjects were treated with GnRH therapy. Moreover, $\approx 90 \%$ of the children which were treated by GnRH therapy were in early puberty, with no PP (26). In those patients, the possibility that the hGH treatment could have influenced the early onset of puberty is unknown (27). This rare combination of GHD and CPP has been reported essentially in patients with septo-optic dysplasia (6-10) and arachnoid cyst (2-5). It has also exceptionally been described after a head trauma $(7,12)$. To our knowledge, although a great phenotypic variability has been demonstrated among patients with GHD associated with ectopic neurohypophysis (23), the coexistence of CPP and GHD has never been reported in patients with ectopic neurohypophysis without extra-pituitary brain malformations (24, 28-30). The occurrence of this intriguing hormonal dysfunction has been reported in only one previous case, a boy, in the early 1970s. Investigations of this patient showed deficiencies of GH, prolactin, and TSH. The boy's brain scan was considered normal, but MRI was not available at that time and it was therefore not possible to obtain a precise description of the hypothalamic-pituitary area (1).

The etiology of this association remains unknown. Hypothalamic lesions may be involved. In patients with arachnoid cysts, damage to the hypothalamic-pituitary axis probably results from the cyst exerting pressure on the hypothalamus (2-5). The extension of anterior

Table 4 Characteristics of the patients at last evaluation.

\begin{tabular}{|c|c|c|c|c|}
\hline Patient & 1 & 2 & 3 & 4 \\
\hline Chronological age (years) & 7.3 & 14.8 & 16.8 & 12.7 \\
\hline Bone age (years) & 11.5 & 14 & 16 & 12.5 \\
\hline Height $(\mathrm{cm})$ & 130 & $183.8^{\mathrm{a}}$ & $161^{\mathrm{a}}$ & 162 \\
\hline Height (SDS) & +1.5 & +2.5 & -0.3 & +1.6 \\
\hline BMI (SDS) & +3.7 & +0.8 & +1.1 & +1.5 \\
\hline Change in BMI since GHD diagnosis (SDS) & +2.8 & +1.8 & +3 & -0.8 \\
\hline Age at LHRH treatment withdrawal (years) & Ongoing treatment & 13 & 12.3 & 11.7 \\
\hline Duration of treatment with LHRH (years) & 2.5 & 3.7 & 4 & 3.2 \\
\hline Pubertal signs & Р 3 T $35 \times 20$ & P5T50 $\times 30$ & P2B4 & P4B3 \\
\hline Menarche & & & + (irregular cycles) & - \\
\hline Testosterone (ng/ml) & 1.6 & 4.6 & & \\
\hline Duration of hGH treatment ${ }^{\mathrm{b}}$ (years) & 7.3 & 9.2 hGH stopped & 10.8 hGH stopped & 11.6 \\
\hline
\end{tabular}

$\mathrm{P}$, pubic hair; $\mathrm{T}$, testis $(\mathrm{mm})$; B, breast development.

adult height.

${ }^{\mathrm{b}}$ Two patients ( 1 and 4 ) were still on hGH treatment at this evaluation. 
midline malformations into the hypothalamus seems likely in patients with septo-optic dysplasia, about half of whom have been reported to have an ectopic neurohypophysis (6-10). In our patients with isolated ectopic neurohypophysis, with no other extra-pituitary area abnormalities of the anterior midline, a similar mechanism may underlie the observed endocrine manifestations.

Only one of our patients had an exaggerated and prolonged plasma TSH concentration response to TRH suggestive of a hypothalamic defect. None of the patients had hyperprolactinemia, which is also known to result from hypothalamic or pituitary stalk dysfunction. As in the only other patient with idiopathic GHD and CPP described to date (1), plasma TSH and prolactin concentrations were very low in one of our patients (with CPP occurring at a very young age), consistent with a primary pituitary disorder. Nevertheless, the obesity or rapid increase in BMI SDS and the psychomotor retardation observed in most of these patients $(n=3)$, together with the hypersomnia and hyperphagia observed in one patient, are more indicative of a hypothalamic etiology. The clinical presentation thus suggests the coexistence of pituitary and hypothalamic developmental defects in at least some cases. This is also consistent with the MRI findings for the three patients with ectopic neurohypophysis and anterior pituitary hypoplasia.

Since the endocrine disease began early in the life of these patients with no reported adverse perinatal events, but with congenital developmental abnormalities on MRI, the coexistence of CPP and GHD in these patients may therefore result from a prenatal developmental event. Abnormalities of the gonadotropic axis stimulating or inhibiting mechanisms in the hypothalamic neurons that may be of neuroendocrine and/or genetic origin, may induce the precocious activation of the gonadotropic axis (31-33). It has been suggested that no isolated pathway is solely responsible for the neuroendocrine control of puberty. This control might be more likely exerted by interconnected regulatory networks (3). Thus, PP might lead to modification of the neuroendocrine interconnected networks involved in puberty control, as shown for hypothalamic hamartoma, a congenital malformation of the basal hypothalamus usually associated with sexual precocity $(31,33)$. These changes may be independent of sex, as the usual female preponderance known in CPP was not observed here or in cases associated with arachnoid cyst or septo-optic dysplasia (2-10).

In conclusion, although one limitation of our study is that our analysis was retrospective, our data emphasize the extremely rare occurrence of this endocrine disorder. These findings highlight the need for vigilance when clinical signs of puberty begin to appear in children with GHD and developmental defects, even though late puberty is more frequently observed than PP in these children. Auxological symptoms may not always be obvious, but acceleration of the growth spurt and an excessive advance in bone maturation, which may occur before the first signs of puberty, may mask growth retardation due to GHD or may be masked by catch-up growth due to hGH treatment. Delays in the initiation of treatment for PP and a lack of GHD diagnosis before the onset of puberty (preventing or restricting hGh treatment) may be deleterious for the patient's adult height. The treatment of both these rare endocrine disorders, occurring here in combination, is likely to be beneficial to affected individuals in terms of both psychological well-being and adult height. Finally, detailed descriptions of phenotypes can enhance our understanding of the disease, making it easier to identify patients likely to benefit from further investigations in collaboration with molecular biologists.

\section{References}

1 Winter JS, De Groot W \& Faiman C. Idiopathic sexual precocity in a boy with growth hormone, prolactin and thyrotropin deficiencies. Journal of Clinical Endocrinology and Metabolism 1974 39 356-363.

2 Brauner R, Pierre-Kahn A, Nemedy-Sandor E, Rappaport R \& Hirsch JF. Pubertés précoces par kyste arachnoïdien suprasellaire, Analyse de 6 observations. Archives Françaises de Pédiatrie 198744 489-493.

3 Mohn A, Schoof E, Fahlbusch R, Wenzel D \& Dorr HG. The endocrine spectrum of arachnoid cysts in childhood. Pediatric Neurosurgery 199931 316-321.

4 Adan L, Bussières L, Dinand V, Zerah M, Kahn A \& Brauner R. Growth, puberty and hypothalamic-pituitary function in children with suprasellar arachnoid cyst. European Journal of Pediatrics $2000159348-355$.

5 Huang H, Ching Tung Y, Tsai W, Kuo M \& Peng S. Arachnoid cyst with GnRH-dependant sexual precocity and growth hormone deficiency. Pediatric Neurology 200430 143-145.

6 Huseman CA, Kelch RP, Hopwood NJ \& Zipf WB. Sexual precocity in association with septo-optic dysplasia and hypothalamic hypopituitarism. Journal of Pediatrics 197892 748-753.

7 Lafranchi SH. Sexual precocity with hypothalamic hypopituitarism. American Journal of Diseases of Children 1979133 739-742.

8 Stewart C, Castro-Magana M, Sherman J, Angulo M \& Collip T. Septo-opic dysplasia and median cleft face syndrome in a patient with isolated growth hormone deficiency and hyperprolactinemia. American Journal of Diseases of Children 1983137 484-487.

9 Hanna C, Mandel S \& Lafranchi S. Puberty in the syndrome of septo-optic dysplasia. American Journal of Diseases of Children 1989 143 186-189.

10 Birkebaek NH, Patel L, Wright NB, Grigg JR, Shina S, Hall CM, Price DA, Lloyd IC \& Clayton PE. Endocrine status in patients with optic nerve hypoplasia: relationship to midline central nervous system abnormalities and appearance of the hypothalamicpituitary axis on magnetic resonance imaging. Journal of Clinical Endocrinology and Metabolism $2003 \mathbf{8 8} 5281-5286$.

11 Sklar A \& Constine LS. Chronic neuroendocrinological sequelae of radiation therapy. International Journal of Radiation Oncology, Biology, Physics 199531 1113-1121.

12 Leiper AD, Stanhope R, Kitching P \& Chessels JM. Precocious and premature puberty associated with treatment of acute lymphoblastic leukaemia. Archives of Disease in Childhood 198762 1107-1112.

13 Attie KM, Ramirez NR, Conte FA, Kaplan SL \& Grumbach MM. The pubertal growth spurt in eight patients with true precocious 
puberty and growth hormone deficiency: evidence for a direct role of sex steroids. Journal of Clinical Endocrinology and Metabolism 199071 975-983.

14 Caisse Nationale d'Assurance Maladie des Travailleurs Salariés. Evaluation des pratiques: enquête nationale inter-régimes. Les traitements par hormone de croissance. Edition Juin 2004.

15 Sempé M, Pedron G \& Roy-Pernot MP. Auxologie, Méthodes et Séquences. Paris: Theraplix, 1970.

16 Rolland-Cachera MF, Cole TJ, Sempe M, Tichet J, Rossignol C \& Charraud A. Body mass index variations: centiles from birth to 87 years. European Journal of Clinical Nutrition 1991 45 13-21.

17 Tanner JM. Growth at Adolescence, pp. 28-39, Oxford: Blackwell, 1978.

18 Greulich WW \& Pyle S. Radiographic Atlas of Skeletal Development of the Hand and the Wrist, 2nd edn. Stanford, CA: Stanford University Press, 1959

19 Tanner JM, Goldstein H \& Whitehouse RH. Standards for children's height at ages 2-9 years allowing for heights of parents. Archives of Disease in Childhood 197045 755-762.

20 Argyropoulou M, Pérignon F, Brunelle F, Brauner F \& Rappaport R. Height of normal pituitary gland as a function of age evaluated by magnetic resonance imaging in children. Pediatric Radiology 199121 247-249.

21 Largo RH, Walli R, Duc G, Fanconi A \& Prader A. Evaluation of perinatal growth, Presentation of combined intra- and extrauterine growth standards for weight, length and head circumference. Helvetica Paediatrica Acta 198035 419-436.

22 Zenaty D, Garel C, Limoni C, Czernichow P \& Léger J. Presence of magnetic resonance imaging abnormalities of the hypothalamicpituitary axis is a significant determinant of the first 3 years growth response to human growth hormone treatment in prepubertal children with nonacquired growth hormone deficiency. Clinical Endocrinology 200358 647-652.

23 Simon D, Hadjiathanasious C, Garel C, Czernichow P \& Léger J. Phenotypic variability in children with growth hormone deficiency associated with posterior pituitary ectopia. Clinical Endocrinology 200664 416-422.

24 Chen S, Léger J, Garel C, Hassan M \& Czernichow P. Growth hormone deficiency with ectopic neurohypophysis: anatomical variations and relationship between the visibility of the pituitary stalk asserted by magnetic resonance imaging and anterior pituitary function. Journal of Clinical Endocrinology and Metabolism $1999842408-2413$.
25 Coste J, Letrait M, Carel JC, Tresca JP, Chatelain P, Rochiccioli P, Chaussain JL \& Job JC. Long term results of growth hormone treatment in France in children of short stature: population, register based study. British Medical Journal 1997315 708-713.

26 Reiter EO, Lindberg A, Ranke MB, Price DA, AlbertssonWikland K, Cowel CT \& Bakker B. The KIGS experience with the addition of gonadotropin-releasing hormone agonists to growth hormone $(\mathrm{GH})$ treatment of children with idiopathic GH deficiency. Hormone Research $2003 \mathbf{6 0} 68-73$.

27 Kamp GA, Waelkens JJJ, De Munick Keiser-Schrama SMPF, Delemarre-van de Waal HA, Verhoeven-Wind L, Zwinderman AH \& Witt JM. High dose growth hormone treatment induces acceleration of skeletal maturation and an earlier onset of puberty in children with idiopathic short stature. Archives of Diseases in Childhood 200287 215-220.

28 Pinto G, Netchine I, Sobrier ML, Brunelle F, Souberbielle JC \& Brauner R. Pituitary stalk interruption syndrome: a clinicalbiological-genetic assessment of its pathogenesis. Journal of Clinical Endocrinology and Metabolism 199782 3450-3454.

29 Tauber M, Chevrel J, Diene G, Moulin P, Jouret B, Olivier I, Pienkowski C \& Sevely A. Long term evaluation of endocrine disorders and effects of GH therapy in 35 patients with pituitary stalk interruption syndrome. Hormone Research $2005 \mathbf{6 4}$ 266-273.

30 Léger J, Danner S, Simon D, Garel C \& Czernichow P. Do all patients with childhood-onset growth hormone deficiency (GHD) and ectopic neurohypophysis have persistent GHD in adulthood? Journal of Clinical Endocrinology and Metabolism 200590 560-656.

31 Jung H \& Ojeda SR. Pathogenesis of precocious puberty in hypothalamic hamartoma. Hormone Research 200257 31-34.

32 Grumbach M. The neuroendocrinology of human puberty revisited. Hormone Research 200257 2-14.

33 Ojeda SR, Lomniczi A, Mastronardi C, Heger S, Roth C, Parent AS, Matagne $\mathrm{V} \&$ Mungenast A. Minireview: the neuroendocrine regulation of puberty: is the time ripe for a systems biology approach? Endocrinology 2006 147 1166-1174.

Received 19 November 2006

Accepted 6 February 2007 